УДК 338.2

DOI: $10.18101 / 2304-4446-2019-4-72-80$

\title{
ИНСТИТУЦИОНАЛЬНАЯ ПРИРОДА ЦИФРОВЫХ ПЛАТФОРМ
}

(C) Рыжкова Марина Вячеславовна

доктор экономических наук, профессор

E-mail: marybox@inbox.ru

(C) Чиков Михаил Владимирович

кандидат экономических наук, доцент

E-mail: chikovmv@mail.ru

Национальный исследовательский Томский государственный университет Россия, 634050, г. Томск, ул. Ленина 30

В статье рассмотрены существующие подходы к анализу и основания цифровых платформ как института. Несмотря на отсутствие общепризнанных концепций институциональной природы цифровых платформ, общим их основанием является экономия на трансакционных издержках. Однако цифровые платформы не только снижают транасакционные издержки, изменяется структура бизнес-процессов и архитектура самих трансакций. Процессы цифровизации и активное развитие цифровых платформ порождают новые виды издержек - сопротивления цифровизации и цифрового сопротивления.

Цифровые платформы обладают уникальным потенциалом и инструментарием для конструирования социальной реальности и институционального проектирования не только хозяйственных, но и всех общественных процессов. По существу, платформы представляют собой новую форму институционализации социально-экономических отношений.

На микроуровне определяющим становится анализ влияния институтов на взаимодействия индивидов в рамках отдельных платформенных решений, в которых вопрос следования определенным правилам поведения на платформе будет составлять ядро научной проблематики в будущем.

Ключевые слова: цифровые платформы; институты; трансакционные издержки; сетевые эффекты; доверие; цифровое сопротивление; цифровизация; институциональное проектирование; институциональная устойчивость; репутационные механизмы.

\section{Для цитирования}

Рыжкова М. В., Чиков М. В. Институциональная природа цифровых платформ // Вестник Бурятского государственного университета. Экономика и менеджмент. 2019. № 4. С. $72-80$.

Масштабные процессы цифровизации все в большей мере определяют интенсивность развития современных рынков. Одним из первых, кто зафиксировал значение этого тренда для экономики, был Николас Негропонте, введя в профессиональный оборот понятие «цифровая экономика» [1], в основе которой лежит активное развитие информационно-коммуникационных технологий и интернетиндустрий. Впрочем сами по себе цифровые технологии мало значимы для экономического анализа, наибольший научный интерес представляют внутренние и внешние эффекты, которые они порождают. Цифровизация охватывает все 
больше новых сфер социально-экономической жизни людей, меняя структуру и качество отношений; многие отрасли, уловив этот тренд, претерпевают сегодня цифровую трансформацию. Ядром вышеназванных процессов является активный переход на цифровые платформы, которые постепенно становятся неотъемлемой частью бизнес-моделей компаний, моделей потребительского поведения, моделей регулирующего воздействия государства и пр.

Несмотря на первенство специалистов в области информационных технологий при исследовании цифровых платформ, представители социо-гуманитарных наук рассматривают данный феномен в рамках сформированных исследовательских парадигм. Вместе с тем в попытке охватить теоретические и методологические контуры исследования цифровых платформ исследователи по-разному определяют ключевые их особенности и каждый раз раскрывают новые аспекты их функционирования.

Теоретические изыскания экономистов раскрывают данный феномен с точки зрения изменения режимов функционирования экономических явлений (фирма, рынок, структура экономики и пр.). Основу для изучения цифровых платформ заложили Ж.-Ш. Роше и Ж. Тироль [2], которые в рамках отраслевой экономики обратили внимание на то, каким образом платформы обслуживают рыночные трансакции и какие сетевые эффекты они порождают. Иными словами, платформы рассматриваются как ключевые игроки многосторонних рынков, которые порождают внешние сетевые эффекты [3-8].

Цифровые платформы позволяют существенно трансформировать режимы функционирования современных рынков (пример рынка такси, аренды жилья, покупки билетов и пр.), а также проектировать и создавать принципиально новые «умные» рынки (шеринговые схемы, схемы совместного использования объектов потребления и пр.) благодаря тому, что они минимизируют рыночные сбои. В основе цифровых платформ лежат более эффективные аллокационные механизмы и механизмы согласования трансакций. Возможность более эффективно распространять информацию, учитывать специфику трансакций и их стоимость, которая может зависеть не только от скорости совершения, но и от того, как будут реализованы другие трансакции, - все это позволяет существенно повысить плотность рынка (для многих рынков этот параметр является определяющим) и создаваемую ценность. В качестве примеров эффективно спроектированных «умных» рынков на основе цифровых платформ можно привести национальные системы подбора донора почек, системы обмена и подбора медицинского персонала в США (National Resident Matching Program - NRMP).

Немногочисленные попытки осмыслить институциональную природу цифровых платформ сводятся к пониманию их как посреднического трансакционного института (организационного аттрактора), функционирующего в условиях гибридной реальности [9]. Вместе с тем мы полагаем, что институциональная природа цифровых платформ логически более сложна и неоднозначна, поэтому цифровые платформы как сложные объекты не сводятся просто к институту посредничества, они определяют одновременно возможности (стимулы) и ограничения, права и обязанности, роли и статусы.

Формирующие основания цифровых платформ как института лежат в сфере индивидуального восприятия, но при этом представляют собой межсубъектную 
материю. В соответствии с теорией Дж. Серля значимую роль в образовании институциональных фактов играет «коллективная интенциональность» [10] - способность индивидов наделять объекты функциональным содержанием в процессе коллективной деятельности и проявляющаяся в виде коллективных намерений, убеждений и желаний. В процессе экономической деятельности участники способны наделять процессы, отношения, организационные структуры и самих субъектов новым статусом и функциями, при этом для реализации функции необходим статус, а для закрепления статуса необходимо его коллективное принятие в течение длительного периода [11]. Особенность цифровых платформ как института состоит в том, что они, как правило, имеют формально заданную систему статусов и функций и для их коллективного принятия не требуется длительного времени.

Информационная природа институтов предполагает использование и координацию разнообразных знаний экономических субъектов. Ф. Хайек [12] в концепции «рассеянного знания» в качестве координирующего элемента экономических взаимосвязей признавал особую значимость институциональных регуляторов, конкуренция которых определяет эффективность экономики и социальный прогресс. Социальные и экономические институты представляют собой информационные механизмы, которые снабжают информацией процессы принятия решений и сообщают об ожидаемых действиях других субъектов контрактации [13].

Каждый институт обладает функцией информационной поддержки, которая состоит в том, что: а) институты хранят в себе межличностные координационные знания, обеспечивающие воспроизводство устойчивых норм); б) институты призваны облегчать для агента сложность контрактации и одновременно объем усилий познавательного характера [14]. Следовательно, информационная функция институтов заключается в снабжении информацией о вероятных действиях экономических агентов, создавая возможности для принятия решений другими агентами.

Несмотря на отсутствие общепризнанных концепций институциональной природы цифровых платформ, общим основанием в современной литературе является понимание того, что они обеспечивают существенное снижение разного рода трансакционных издержек и способны существенно перестроить структуру современных рыночных отношений. Однако с точки зрения анализа цифровых платформ в этой логике обнаруживается разрыв между идеей того, что институты призваны минимизировать трансакционные издержки, и идеей, что институты, будучи устойчивыми нормами, рассматриваются как факторы, определяющие транзакционные издержки. Преодолеть этот разрыв в анализе цифровых платформ как института можно, если в качестве единицы анализа рассматривать трансакцию как «действие, предпринимаемое, когда нечто, например товар, социальное отношение или информация, передается между индивидами или другими социальными единицами и обладает внешним действием на реципиента». Такой подход выглядит вполне естественным для анализа цифровых платформ, поскольку в процессе прямого взаимодействия и обмена между двумя или несколькими группами внешних пользователей они признают друг в друге независимых партнеров. 
Снижение трансакционных издержек приводит к расширению вариантов и качества обмена, но те только. Цифровые платформы меняют архитектуру трансакции и некоторые ее признаки. Существующие подходы к пониманию трансакции предполагают, что в ее основе лежит перемещение ресурсов (в том числе обмен данными, информацией) или санкционированных прав собственности [15; 16]. Соответственно, чтобы осуществить рыночную трансакцию необходимо, прежде всего, понести информационные издержки, издержки ведения переговоров и т. д. Предполагается, что субъекты принятия решений не могут знать, с кем и на каких условиях будет совершена сделка [17]. Иными словами, теории фирм, агентских отношений и прав собственности исходят из того, что информация является дорогой, а потому она распределяется асимметрично и неполно. Полная же информация будет бесконечно дорогой. Следовательно, контракты на сделки обязательно являются неполными и оставляют некоторую степень остаточной неопределенности и потенциального морального риска и неблагоприятного выбора. Однако, что если ключевые предпосылки институционалистов о неполноте информации и рыночной неопределенности в аспекте развития цифровых платформ и блокчейн-технологий существенно ослабевают? Тогда неоклассические модели становятся более реальными.

Лежащая в основе трансакции конфликтность, обусловленная неполнотой информации и отсутствием возможности совместного потребления, с одной стороны, ослабевает, поскольку цифровые платформы допускают эту возможность. Сетевые эффекты от устойчивого взаимовыгодного взаимодействия участников цифровой платформы обеспечивают воспроизводство ценности для каждого из них и способны порождать новые механизмы доверия [18]. Однако, с другой стороны, в цифровых платформах изначальные связи между пользователями, как и многие взаимодействия, происходят исключительно в киберпространстве, поэтому анонимность пользователей повышает риски, хотя, с другой стороны, наличие репутации их существенно снижает. Кроме того, конфликтность развития в рамках цифровых платформ может увеличиваться благодаря тем же сетевым эффектам, когда для разных пользователей могут возникать различия в условиях доступа на платформу, что может вызвать их недовольство и сопротивление цифровизации.

Следовательно, цифровые платформы не просто снижают трансакционные издержки, а изменяют их структуру. Одни виды трансакционных издержек существенно снижаются (издержки поиска информации, измерения, заключения контракта, издержки контроля), другие, наоборот, возрастают (например, издержки спецификации и защиты прав собственности). Впрочем возможность применения блокчейн-технологий в сфере спецификации и защиты прав собственности могут в перспективе свести соответствующие издержки к минимуму. Однако снижение одних издержек может сопровождаться появлением других видов трансакционных издержек.

В частности, процессы цифровизации и активное развитие цифровых платформ порождают новые виды издержек - сопротивления цифровизации и цифрового сопротивления. Издержки сопротивления цифровизации - это трансакционные издержки ex ante, возникающие до момента совершения платформенных трансакций и предполагающие, что экономические агенты по разным при- 
чинам не готовы обращаться к цифровым решениям и, в частности, к платформам (например, в случае ценностного выбора человека в пользу защиты персональных данных). Своего рода это издержки перехода из оффлайн в онлайн.

Издержки цифрового сопротивления - это трансакционные издержки ex post, возникающие уже после совершения платформенных трансакций и предполагающие сопротивление экономических агентов и конфликтность внутри цифрового пространства. Например, когда цифровая платформа не способна эффективно скоординировать существующие или вновь возникающие взаимодействия с пользователями и создать равные условия совершения трансакций. Цифровое сопротивление - результат конфликтного сближения неформальных норм и формальных структур цифровых платформ.

Помимо снижения трансакционных издержек цифровые платформы способны вовлекать недоиспользованные ресурсы и активы [9]. Возможность подключения к платформенным трансакциям разного рода материальных и нематериальных ресурсов и активов создает условия и возможности для появления принципиально новых видов взаимодействий и ценностей для участников платформы. Это может стать основой для появления совершенно новых индустрий и одновременно обострить проблему цифрового сопротивления.

Анализируя гибридную институциональную природу цифровых платформ, закономерно возникает вопрос об их институциональной устойчивости, т. е. возможности эволюции и изменения их во времени. Полагаем, что вопрос институциональных изменений (или искажений) определяется тем, в какой степени неформальные нормы получат развитие в формализованной и, как правило, четко алгоритмизированной институциональной структуре цифровых платформ. Насколько вероятно, что возникнет ситуация, когда платформа полностью отразит все аспекты взаимодействия и достигнет положения институционального равновесия? В соответствии с новой институциональной экономической теорией институциональное равновесие устойчиво, если развитие неформальных норм «наполняет» формальные структуры, не разрушая их первоначальной архитектуры, и если после нарушения исходного равновесия будет автоматически достигаться новое равновесие [17]. Иными словами, институциональная устойчивость цифровых платформ определяется их адаптационными возможностями.

Адаптивность цифровых платформ создается не только благодаря наличию сетевых эффектов и огромных пользовательских сообществ, но и тем, что они способны подключать людей, устройства и различные киберфизические системы к единому интеллектуальному информационному пространству посредством совокупности технической инфраструктуры, датчиков, платформенных технологий, модулей, сетей, программ и приложений для сбора и обработки больших данных и т. п. Все это дает возможность держателям платформы использовать механизмы мгновенной циклической обратной связи с формируемыми ими сообществами пользователей, ориентируясь на рыночные сигналы (отзывы о качестве продукции и услуг, репутации поставщиков и потребителей, уровни спроса и предложения услуг в реальном времени и т. п.). Благодаря применению цифровых технологий время, необходимое для установления нового равновесия, существенно снижается, поскольку держатели цифровых платформ могут относительно быстро оптимизировать ее формальную структуру в случае, если она не 
отвечает интересам (ценностям) пользовательских сообществ и наблюдается цифровое сопротивление. Таким образом, отличительной особенностью цифровых платформ является их относительная институциональная устойчивость и уникальная гибкость в масштабировании, которые благодаря применению цифровых технологий, цифровому представлению и передачи информации и возможности быстро менять свою формальную архитектуру формируют высочайший уровень их адаптивности.

Следует оговориться, что степень адаптивности и устойчивости у различных видов платформ может быть различной. Адаптивность платформы будет определяться тем, насколько эффективно выстроены механизмы доверия, и тем, насколько формальная архитектура платформы способна учитывать человеческую природу и оставаться открытой для неминуемого роста неформальных процессов и механизмов защиты.

Механизмы доверия становятся ключевым управляемым элементом в структуре трансакций, совершаемых на цифровых платформах. Доверие показывает, насколько комфортно ощущают себя пользователи в процессе совершения взаимных трансакций на платформах, несмотря на возникающие риски. Успех широкого круга платформ (Lyft, Sidecar, Uber, Airbnb, DogVacay, Rover, Feastly, RelayRides, Getaround, Boatbound, HomeAway, Zilok) основан именно на этом.

В цифровых платформах доверие формируется через механизмы курирования и взаимной оценки (репутационные рейтинги). Курирование участников платформы (пример платформы Airbnb) позволяет снижать риск оппортунизма, a peпутационные рейтинги, будучи формой социального контроля и саморегулирования, снижают информационную асимметрию и повышают защиту и безопасность потребителей. Сближение формальных и неформальных норм через механизмы доверия способно полностью устранить проблему цифрового сопротивления.

Однако доверие в цифровых платформах имеет противоречивую двойственность: с одной стороны, четко алгоритмизированные механизмы и процедуры платформ формируют у пользователей своего рода сверхдоверие, с другой стороны, совершенствование платформ в сторону более персонифицированного подхода к пользователям (в том числе через применение искусственного интеллекта) может привести к снижению доверия из-за страха «сверханализа» самих себя.

В спектре институциональных альтернатив цифровые платформы представляют собой своего рода гибридный институт, обладающий следующими характеристиками:

1. Уникальное сочетание внутри платформ информационных систем и технологий создает особый режим потоков информации и осуществления трансакций, позволяющий пользователям получать индивидуальную и коллективную ценность благодаря огромным пользовательским сообществам; осуществлять взаимодействие в дискретном режиме без условия необходимости одновременной доступности друг для друга пользователей различных сторон и вовлекать в рыночные трансакции ранее не задействованных игроков, а также их специфические ресурсы и активы. 
2. Цифровые платформы обеспечивают обезличенный обмен между двумя или несколькими группами внешних пользователей в рамках единой цифровой экосистемы алгоритмизированных отношений. Причем функцию защиты здесь выполняет не государство, а сама платформа, которая часто берет на себя риски и издержки оппортунизма (например, страховки на платформе Airbnb, страховка пассажиров Яндекс Такси). Выстраиваемые системы контроля, включающие в том числе формализованные репутационные механизмы, позволяют платформам минимизировать издержки контроля. Кроме того, присущие платформам сетевые эффекты субординируют поведение экономических субъектов в рамках совершаемых трансакций. Пользователям часто самим невыгодно нарушать условия соглашений.

3. Цифровые платформы обладают уникальным потенциалом и инструментарием для конструирования социальной реальности и институционального проектирования не только экономических, но и всех общественных процессов. По существу платформы представляют собой новую форму институционализации социально-экономических отношений.

Все это в совокупности позволяет сформулировать ключевое, на наш взгляд, направление последующего исследования цифровых платформ, которое состоит в анализе стимулов индивидуального выбора и оценке роли институциональных ограничений в этом выборе. На микроуровне определяющим становится анализ влияния институтов на взаимодействия индивидов в рамках отдельных платформенных решений, в которых вопрос следования определенным правилам поведения на платформе будет составлять ядро научной проблематики.

Исследование выполнено при финансовой поддержке РФФИ в рамках научного проекта № 19-010-00352: Рынок иифровых платформ: сиенарии преодоления потребительского сопротивления цифровизащии,

\section{Литература}

1. Negroponte N. Being Digital. NY: Knopf, 1995. 256 p.

2. Rochet J., Tirole J. Two-Sided Markets // Journal of the European economic association. 2003. Vol. 1, № 4. Pp. 990-1029.

3. Armstrong M. Competition in two-sided markets // The RAND journal of economics. 2006. Vol. 37, No. 3. Pp. 668-691.

4. Caillaud B., Jullien B. Chicken and egg: Competition among intermediation service providers // RAND Journal of economics. 2003. Vol. 34, No. 2. Pp. 309-328.

5. Rochet J., Tirole J. Two-Sided markets: a progress report // The RAND Journal of economics. 2006. Vol. 37, No. 3. Pp. 645-667.

6. Шаститко А. Е., Маркова О. А. Эффекты становления и функционирования многосторонних рынков: подходы к исследованию // Общественные науки и современность. 2019. №. 3. С. 52-65.

7. Яблонский С. А. Многосторонние платформы и рынки: основные подходы, концепции и практики // Российский журнал менеджмента. 2013. Т. 11, № 4. С. 57-78.

8. Рыжкова М. В. Концептуализация феномена «цифровая платформа»: рынок или бизнес? // Вестник Томского государственного университета. Экономика. 2019. № 47. C. $48-66$.

9. Осипов Ю. М., Юдина Т. Н., Гелисханов И. 3. Цифровая платформа как институт эпохи технологического прорыва // Экономические стратегии. 2018. № 5. С. $22-29$. 
10. Searle J. R. Social ontology: Some basic principles // Anthropological Theory. 2006. Vol. 6, No 1. Pp.12-29.

11. Чиков М.В. Анализ трансформации институтов: методология исследования // Вестник Томского государственного университета. 2007. № 294. С. 212-214.

12. Хайек Ф. Индивидуализм и экономический порядок. М.: Изограф, 2000. $256 \mathrm{c}$.

13. Newman G. An Institutional Perspective on Information // International Social Science Journal. 1976. № 28. P. 474.

14. Langlois R.N. Rationality, Institutions and Explanation // R. N. Langlois (ed.) Economics as a Process: Essays in the New Institutional Economics. New York: Cambridge University Press. P. 237.

15. Williamson O. E. The Economic Institutions of Capitalism. The Free Press. New York. 1985. P. 1.

16. Commons J. R. Institutional Economics // Its Place in Political Economy. Macmillan. New York, 1934. P. 58.

17. Фуруботн Э. Г., Рихтер Р. Институты и экономическая теория. Достижения новой институциональной экономической теории: пер. с англ. / под ред. В. С. Катькало, Н. П. Дроздовой. СПб.: Издат. дом С.-Петерб. гос. ун-та, 2005. Вып. XXXIV. С. 59.

18. Паркер Дж., Маршалл ван Альстин, Санджит Чаудари. Революция платформ. Как сетевые рынки меняют экономику — и как заставить их работать на вас / пер. с англ. Е. Пономаревой. М.: Манн, Иванов и Фербер, 2017. С. 77.

\title{
INSTITUTIONAL NATURE OF DIGITAL PLATFORMS
}

\author{
Marina V. Ryzhkova \\ Dr. Sci. (Econ.), Prof. of Economics Department, \\ Institute of Economics and Management \\ National Research Tomsk State University \\ 30 Lenina St., Tomsk 634050, Russia \\ E-mail:marybox@inbox.ru

\section{Mikhail V. Chikov} \\ Cand. Sci. (Econ.), A/Prof. of Economics Department, \\ Institute of Economics and Management \\ National Research Tomsk State University \\ 30 Lenina St., Tomsk 634050, Russia \\ E-mail: chikovmv@mail.ru
}

The article considers the grounds of digital platforms as an institution, and the existing approaches to their analysis. Despite lack of the conceptions of the institutional nature of digital platforms, their common ground is transaction cost savings. However, digital platforms not only reduce transaction costs, but also change the structure of business processes and the architecture of the transactions themselves. Digitalization processes and the active development of digital platforms give rise to new types of costs - the costs of resistance to digitalization and the costs of digital resistance.

Digital platforms have unique potential and tools for constructing social reality and institutional designing not only economic, but also all social processes. Actually, platforms represent a new form of institutionalization of socio-economic relations. 
At the micro level the determining factor is the analysis of the institutions' impact on the interactions of individuals within individual platform solutions, where conforming to certain rules of behavior on the platform will form the core of future scientific problems.

Keywords: digital platforms; institutes; transaction costs; network effects; trust; digital resistance; digitalization; institutional designing; institutional sustainability; reputational mechanisms. 